\title{
O loteamento de terrenos urbanos e terras rurais.
}

\author{
Waldemar Ferreira \\ Professor Emérito da Faculdade de Direito da \\ Universidade de São Paulo.
}

\section{$\S 1.0$}

1. A disciplina legislativa do loteamento de terrenos para a venda a prestações. 2. A aprovação do projeto e planos de loteamento de terras rurais pelas autoridades estaduais e municipais. 3. O regime dos loteamentos rurais pelas posturas municipais.

\section{$\S 2.0^{\circ}$}

4. A natureza urbana ou rural da propriedade imobiliária. 5. O retalhamento de imóvel situado fora do perímetro urbano.

\section{$\S 3.0$}

6. O plano de loteamento de terrenos destinados a moradias e os planos urbanísticos municipais. \%. A elaboração dos programas particulares de desenvolvimento urbano.

\section{$\S 40^{\circ}$}

8. $O$ direito de disposição do proprietário de imóveis. 9 . $A$ divisão de imóvel agrícola em glebas autônomas. 10. A inexistência de pena para o loteador de imóvel rural para venda de chácaras a prestações e anúncios públicos.

$$
\S 5.0
$$

11. A inscrição no Registro de Imóveis das promessas de compra e venda de imóveis. 12. O processo especial de 
rescisão do compromisso registrado. 13. A substituição da averbação pela inscrição. 14. Os efeitos dos compromissos sem cláusula de arrependimento.

1. Dispondo sôbre o loteamento e a venda de terras rurais ou terrenos urbanos, cujos proprietários se proponham a vendê-los em lotes, por oferta pública, mediante pagamento do preço a prazo, em prestações periódicas e sucessivas - o Decreto-lei $n .^{\circ} 58$, de 10 de dezembro de 1937, instituiu regime especial, com o objetivo de resguardar o interêsse dos que houvessem de adquirir os lotes, na medida do possível.

Para êsse efeito, obrigou os proprietários, antes de fazer a exposição à venda ao público da área loteada, a proceder ao depósito, no cartório do Registro de Imóveis da circunscrição respectiva; de pormenorizado relatório, acompanhado de plano, planta e documentos comprobatórios do direito de propriedade das terras urbanos ou terrenos urbanos.

Tratando-se, estabeleceu o $\S 10^{\circ}$ do art. $10^{\circ}$ daquela lei, de propriedade urbana, o plano e planta do loteamento devem ser aprovados prèviamente pela Prefeitura $\mathrm{Mu}-$ nicipal, ouvidas, quanto ao que lhes disser respeito, as autoridades sanitárias e militares, observando-se esta providência quando se tratar de modificação do plano primitivo.

2. Discute-se, isso posto, se, para efeito de loteamento rural (por localização e destinação) se faz necessária a prévia aprovação de planta do loteamento na Prefeitura, Secretaria da Saúde e Ministérios.

Ora, em primeiro lugar, a lei não alude à Secretaria da Saúde e Ministérios, senão apenas "às autoridades sanitárias"; e isso mesmo "quanto ao que lhes disser respeito". 
Para que, portanto, essas autoridades possam ser ouvidas, é indispensável que, por fôrça de lei, pois ninguém é obrigado a fazer ou a deixar de fazer alguma coisa senão em virtude de lei, esteja a área loteada sujeita a interferência daquelas autoridades.

Nem por outro motivo o regulamento expedido pelo Decreto $\mathrm{n} .^{\circ} 3.079$, de 15 de setembro de 1938 , preceituou, no $\& 3 .^{\circ}$ de seu art. $1 .^{\circ}$, que "a Prefeitura e as demais autoridades ouvidas disporão de noventa dias para pronunciar-se, importando o silêncio na aprovação", acrescentando que "a impugnação deverá ser fundamentada em disposições de leis, regulamentos ou posturas, ou no interêsse público".

Evidentemente, e em segundo lugar, a lei se refere à aprovação, pela Prefeitura Municipal, do plano e planta do loteamento, "tratando-se de propriedade urbana". Não se referiu ao loteamento da "propriedade rural".

3. Não é de inadmitir a hipótese todavia da cxistência de lei ou postura municipal estabelecendo normas e diretrizes para o loteamento das propriedades rurais dentro do território municipal, a bem do interêsse público; e caso será então da existência de lei, em virtude da qual o plano e o projeto de loteamento rural deverão ser aprovados pela Prefeitura Municipal, a fim de verificar-se sua concordância com os ditames da lei municipal.

É de notar, neste particular, que a Lei federal $n .^{\circ}$ 2.874, de 19 de setembro de 1956, que dispôs sôbre a mudança da Capital Federal do Rio de Janeiro para Brasília, em seu art. 28, preceituou que "os lotes de terras em que se dividirem, a partir da vigência desta lei, as propriedades rurais existentes até uma distância de trinta quilômetros do lado externo da linha perimétrica do novo Distrito Federal, em áreas inferiores a vinte hectares, só poderão ser inscritos no Registro Imobiliário e expostos à venda depois de dotados os logradouros públicos dos serviços de água encanada, luz elétrica, esgotos sanitários, meios fios e pavimentação asfáltica". 
Eis lei federal a dispôr sôbre loteamentos rurais fora da linha perimétrica do Distrito Federal, dentro de faixa dela circundante até trinta quilômetros. Discutiu-se a validade dêsse dispositivo, é certo, e se deu pela sua invalidade, entre outros motivos, por sua inconstitucionalidade, por ser a matéria da competência legislativa municipal e não federal.

Bem é de ver, pois, que existindo lei municipal regulando os loteamentos rurais, carecerá o plano de loteamento rural de aprovação da Prefeitura Municipal.

\section{$\S 2{ }^{\circ}$}

4. Debate-se se o retalhamento em chácaras ou pequenas áreas pode ser considerado rural.

Inequivocamente, a Lei n. $^{\circ} 58$ distinguiu as "terras rurais" dos "terrenos urbanos", colocando êstes dentro do perímetro urbano e aquelas além da linha perimétrica das cidades ou vilas.

Desde tempos muito antigos se há discutido acerca da natureza urbana ou rural dos imóveis por natureza e ato humano, havidos como prédios; e as opiniões se dividiram adotando uns o critério da destinação e outros o da situação.

Houve o Conselheiro Ribas como urbanas quaisquer porções de solo situado dentro dos limites das cidades, vilas e povoações, como chácaras, quintais e jardins. Ademais, todos os edifícios cobertos situados dentro daqueles limites, qualquer que seja a sua denominação, forma, matéria e destino, uma vez que sejam fixados no solo de modo que se não possam tirar sem se destruirem. $\mathrm{E}$ entre os prédios rurais, que qualificou de rústicos, os terrenos situados fora dos limites das cidades, vilas e povoações, destinados à agricultura, qualquer que seja a sua extensão e estado de aproveitamento, abrangendo as 
datas de terras e águas minerais, estejam ou não em uso e aproveitamento e até os edifícios situados fora daqueles limites destinados à morada dos agricultores ${ }^{1}$.

A Consolidação das Leis Civís de Teixeira Freitas, no art. 30, também reputou prédios rústicos os terrenos, destinados para agricultura, ou sejam grandes ou pequenos, cercados ou não cercados, cultivados ou incultos, como sesmarias, fazendas, estâncias, sítios; as casas de continuada morada dos fazendeiros e agricultores, os paióis, celeiros, armazéns, adegas, currais, cavalariças, senzalas, barracas e cabanas; os engenhos, fábricas e quaisquer oficinas; os moínhos d'água e de vento, que não forem portáteis; os ranchos, telheiros, aquedutos, canais, portos e quaisquer edifícios, de qualquer denominação, forma e construção que sejam, quando imóveis; as datas de terras e águas minerais, estejam ou não em uso e aproveitamento.

Recentes leis se ocuparam do problema.

Dispondo sôbre a organização da vida rural, o Decreto -lei n. 7.449 de 9 de abril de 1945, considerou o que chamou de estabelecimento rural o "imóvel situado dentro ou fora dos limites urbanos, que se destine ao cultivo da terra, à extração de matérias primas de origem vegetal, à criação, à recriação ou melhoria de animais e á indústria conexa ou acessória dos produtos derivados dessas atividades".

Adotou o texto o critério da destinação: tanto pode ser rural o prédio situado dentro do perímetro urbano, quanto o localizado fora dêste, demarcado pela lei municipal.

Sobreveio logo depois o Decreto-lei n. ${ }^{\circ} 8.127$, de 24 de outubro de 1945, alterando a redação daquele dispositivo, em ponto fundamental, qual o de definição de estabelecimento rural.

1. Antônio Joaquim Ribas, Curso de Direito Civil Brasileiro, Rio de Janeiro, 1918, Jacinto Ribeiro dos Santos, Livreiro Editor, p. 338 . 
Éste, ficou expresso no art. $3 .^{\circ}$, é "o imóvel destinado ao cultivo da terra, à extração de matérias primas de orígem animal e vegetal, à criação, à recriação, à invernagem ou engorda de animais e à industrialização conexa ou acessória dos produtos dessas atividades".

Excluiu-se, do dispositivo anterior, a cláusula "dentro ou fora dos limites urbanos", que nele se continha; e a exclusão se verificou com o objetivo de pôr-se o texto em consonância com a realidade da inexistência de terras rurais, pròpriamente ditas, dentro dos perímetros urbanos. $\mathrm{E}$ muito mais ainda do que os dois atos legislativos chamaram de "estabelecimento rural".

5. O retalhamento de imóvel, situado fora do perímetro urbano, em áreas de dois mil quilômetros quadrados destinadas à formação de chácaras, inequìvocamente se qualifica como loteamento de terras rurais, no sentido que a estas atribuiu a Lei $\mathrm{n}^{\circ}$ 58, de 10 de dezembro de 1937.

De resto, chácaras são definidas pelos dicionários como casas de campo, com jardim e horta, às vêzes com horta e pomar, nas zonas rurais. Quintas. Granjas. Sítios.

\section{$\S 3 .^{\circ}$}

6. Difere certamente o loteamento de terrenos urbanos do loteamento de terras rurais.

O loteamento de terrenos urbanos, com o propósito de facilitar aos de fortuna modesta a aquisição de casa própria, quando não a formação de centros industriais, instituindo bairros nos arrabaldes das vilas e cidades, tem que se submeter ao regime dos códigos de obras ou leis e planos urbanísticos destas ou daquelas.

Exige a lei, por isso mesmo, a elaboração do plano do loteamento, de que conste "o programa de desenvolvimento urbano", com a planta do imóvel, com os requisitos técnicos e legais, indicando "a situação, as dimensões e 
a numeração dos lotes, as dimensões e a nomenclatura das vias de comunicação e espaços livres, as construções e benfeitorias e as vias públicas de comunicação".

Tratando-se de propriedade urbana, estabelece a lei, “o plano e planta do loteamento devem ser prèviamente aprovados pela Prefeitura Municipal, ouvidas, quanto ao que lhes disser respeito, as autoridades sanitárias e militares".

7. E diferente o loteamento de terras rurais.

No plano e planta dêste se formulará o programa "de aproveitamento industrial ou agrícola", ministrando "informações sôbre a qualidade das terras, águas, servidões ativas e passivas, estradas e caminhos, distância da sede do município e das estradas de transporte de mais fácil acesso".

Quando o loteamento se destinar a venda das chácaras, granjas ou sítios, deverá ser inscrito, para os efeitos legais, com observância dos dispositivos do já referido Decreto-lei $n .^{\circ} 58$; e é evidente que inexistindo ruas, praças e espaços livres, todavia se terão estradas, caminhos, atravessadouros, que poderão ser de uso exclusivo das glebas que então se formarem.

\section{$\S 4 .^{\circ}$}

8. É direito do proprietário o de usar, gozar e livremente dispôr de seus bens.

Lícito lhe é, dessarte, dispôr de sua propriedade rural, no todo ou em partes. Parcialmente é possível destacar parte dela, a qualquer momento, a fim de a vender, pelo preço e condições, que ajustar. Feita a primeira, outras vendas sucessivas poderá realizar, tranqüila e legìtimamente.

Quando todavia se propuser a dividir sua propriedade em lotes - sejam glebas, chácaras, granjas, herdades, 
sítios - a fim de os vender em prestações periódicas e sucessivas para pagamento do preço, oferecendo-as ao público, cumpre-lhe observar os dispositivos do Decreto-lei n. $^{\circ} 58$ e de seu regulamento, a fim de gozar das vantagens, que êle confere, assegurando, ao mesmo passo, a garantia dos interêsses dos que atenderem a sua oferta pública.

9. Nada obsta a que o proprietário do imóvel agrícola faça levantar sua planta por técnico de sua confiança e o divida em glebas adequadas ao cultivo agrícola, de qualquer espécie, a fim de as vender particularmente, sem propaganda e oferta pública, estabelecendo o sistema de intercomunicação delas e de acesso livre de cada uma às estradas públicas, às rodovias oficiais, criando até em favor delas as necessárias servidões ativas e passivas.

Obrigado não será a observar as prescrições do Decreto-lei n. ${ }^{\circ}$ 58. Ajustada a venda de tal ou qual lote, fará lavrar a respectiva escritura de compromisso, revestida das formalidades legais, exarando nela tôdas as cláusulas e condições pactuadas. Poderá êle até, se lhe convier, mandar elaborar minuta daquela escritura, datilografada ou mesmo impressa, que submeterá à aceitação de quantos se propuserem comprar uma ou mais glebas, introduzindo-se, na escritura definitiva, as avenças que vierem a ser combinadas.

Essa prática é de inteira legitimidade e de usança de muita freqüência, por ser peculiar à liberdade de contratar. Não incide em censura jurídica de nenhuma espécie, de qualquer natureza. O proprietário não está impedido por lei de dispôr de seus bens, como melhor lhe aprouver.

10. Inexiste pena para o loteador de imóvel rural que venda suas chácaras a prestações e mediante oferta pública, sem que o tenha inscrito nos têrmos do Decreto-lei n. ${ }^{\circ} 58$ e de seu regulamento.

Nenhuma pena estabeleceu aquêle ato legislativo. Também não a poderia ter estatuído o seu regulamento. 
Quando o projeto, que naquele Decreto-lei se convolou, se discutiu na Câmara dos Deputados, emenda se lhe apresentou a fim de dêle se suprimir a cláusula "por oferta pública", que pareceu inútil ou desvantajosa.

Defendendo o projeto, seu autor aduziu considerações que ora se relembram.

"Teve o projeto em vista", escreveu, "disciplinar os contratos de compromisso de venda de terrenos loteados mediante ofertas públicas, sem nutrir o propósito de, por qualquer modo, impedir que ela se faça particularmente, sem publicidade alguma. Todo proprietário de terrenos pode loteá-los e vendê-los se, como e quando quizer, a prazo ou à vista, sem que ninguém possa a isso opôr-se. Desde que, porém, pretenda oferecer os seus lotes em público, por anúncios na imprensa, cartazes, boletins, etc., apregoando-os pela radiofonia ou por outros meios de publicidade, nada mais natural é que êsse gênero de negócio seja convenientemente regulado. Quem se propõe comprar um terreno não deixa de examinar os títulos de domínio do vendedor e de exigir-lhe a apresentação dos documentos, que o projeto determina que sejam depositados no cartório do registro imobiliário. Mas os compradores de lotes a prazo, de parcos recursos no mais das vêzes, não estão em condições de proceder a êsse exame de títulos de domínio ou de solicitá-lo a advogados ou juristas. Para evitar que sejam surpreendidos, como tem acontecido, com prejuízo resultante da dificuldade dêsse exame, foi que o projeto estabeleceu o depósito dos títulos e plantas necessários para adquirir cada um, com o lote de seu agrado, o relativo sossêgo do negócio.

"De resto, e fique isso bem claro, não estabeleceu o projeto, nem de seus articulados se pode deduzir tal absurdo, a pena de nulidade para os contratos que celebrarem os loteadores de terrenos que se não submeterem aos seus dispositivos. Não há nulidade sem que a lei a determine. Estabelece êle um sistema de garantias em favor dos contratantes, quando cumprirem seus preceitos. Os que não 
se acharem nessas condições não poderão gozar delas e eis porque o art. 21 do projeto prescreve que "nenhuma ação ou defesa se admitirá, fundada nos dispositivos desta lei, sem apresentação dos documentos comprobatórios do registro especial por ela instituído" ${ }^{2}$.

\section{$\S 50^{\circ}$}

11. Pelo preceituado no art. 186 do Decreto n. $^{\circ}$ 4.857, de 9 de novembro de 1939, que dispôs sôbre os registros públicos, no livro $n .^{\circ} 4$, de Registros diversos, serão registrados todos os demais atos não especificados, "além da promessa de compra e venda (art. 178, a, n. XIV)"; e por êste dispositivo, está sujeita a inscrição “da promessa de compra e venda de imóvel não loteado, cujo preço deva pagar-se a prazo, em uma ou mais prestações, bem como as escrituras de promessas de venda de imóveis em geral (art. 22 do Decreto-lei n. $^{\circ} 58$, de 19 de dezembro de 1937, e Decreto n. ${ }^{\circ}$ 3.079, de 15 de setembro de 1933)".

12. Ao que havia disposto o art. 22 do Decreto-lei n. ${ }^{\circ}$ 58, acima referido, as escrituras de compromisso de compra e venda de imóveis não loteados, cujo preço devesse pagar-se a prazo, em uma ou mais prestações, se averbariam à margem das respectivas transcrições, para os efeitos daquela lei.

Ampliou o regulamento expedido pelo Decreto $\mathbf{n}^{\circ}$ 3.079 o dispositivo do art. 22, para incluir nele "as escrituras de promessa de venda de imóveis em geral”, dando-lhe maior amplitude.

Pelo sistema daquela lei e respectivo regulamento, e no art. 14, se estabeleceu processo especial, naquela dependente de decisão judicial e neste de simples ato do

2. WALDEMAR FerReira, $O$ loteamento $e$ a venda de terrenos em prestações, São Paulo, 1938, Emprêsa Gráfica da Revista dos Tribunais, p. 83, n.o 1 . 
oficial do Registro de Imóveis, para a rescisão da escritura de compromisso, por falta de pagamento das prestações do preço, por efeito da conversão dos compromissários em mora, e cancelamento da averbação.

13. Sobrevindo o Decreto n. 4.857 , de 9 de novembro de 1939 , a situação se modificou, com a exigência, em vez da averbação, da inscrição no Registro de Imóveis da promessa de compra e venda de imóvel não loteado, cujo preço se houvesse de pagar a prazo, em uma ou mais prestações.

Modificou-se a situação porque tendo sido regulado o cancelamento da averbação de tais escrituras, mas tendo a averbação se substituído pela inscrição, o processo daquele cancelamento se tornou inócuo, pela supressão da averbação.

No atinente ao cancelamento da inscrição, e nos termos do art. 289, estabeleceu o Decreto $n^{\circ} 4.957$, que o cancelamento poderá ser total ou parcial e se referir a qualquer dos atos de registro, sendo promovido pelos interessados, mediante sentença definitiva, ou documento hábil, ou ainda a requerimento de ambas as partes, se capazes e conhecidas do oficial.

14. Acresce que a Lei $\mathrm{n}^{\circ}$ 649, de 11 de março de 1949 , dando nova redação ao art. 22 da Lei n. $^{\circ} 58$, de 10 de dezembro de 1937, lhe alterou o conteúdo, consideràvelmente.

"Os contratos", preceituou, "sem cláusula de arrependimento, de compromisso de compra e venda de imóveis não loteados, cujo preço tenha sido pago no ato de sua constituição ou deva sê-lo em uma ou mais prestações, desde que inscritos em qualquer tempo, atribuem aos compromissários direito real oponível a terceiros e lhes confere o direito de adjudicação compulsória nos têrmos dos arts. 16 desta lei e 346 do Código do Processo Civil”. 
Modificou-se dessarte fundamentalmente o dispositivo inicial, que submetia, pela averbação, a escritura de compromisso de venda e compra de imóvel não loteado ao regime da Lei n. ${ }^{\circ}$ 58, para todos os seus efeitos ${ }^{3}$.

Agora, a inscrição daquela escritura produz sòmente dois efeitos daquela lei: ceiros;

a) o direito real, por ela instituído, oponível a ter-

b) a adjudicação compulsória do compromisso de venda do imóvel não loteado.

3. Insta acrescentar que a Lei n..$^{\circ} 1.297$, de 16 de novembro de 1951, art. 15, veio obrigar os proprietários de imóveis rurais, destinados ว̀. venda em lotes, a apresentar ao Departamento da Receita, na capital, e à repartição fiscal local, no interior, até 31 de março de 1952, uma planta de loteamento, assinada por engenheiro registrado no Conselho de Engenharia e Arquitetura, com firma reconhecida, acompanhada de relação dos adquirentes ou compromissários compradores e respectivos endereços.

Os loteamentos de imóveis rurais, a partir de 31 de março de 1952, seriam igualmente comunicados, dentro de trinta dias contados de seu registro em cartório.

Os contratos de compr e venda e de compromissos, celebrados a partir daquela data, comunicar-se-iam mensalmente.

Isso - é de notar - no Estado de São Paulo, onde se promulgou aquela lei, de caráter financeiro. 